REVIEW SERIES

\title{
Chronic obstructive pulmonary disease c2: Pathology and biochemistry of emphysema
}

\author{
J C Hogg, R M Senior
}

Thorax 2002;57:830-834

The pathology and pathogenesis of emphysema are reviewed, with particular reference to the proteina se-antiproteinase hypothesis.

aennec first described pulmonary emphysema from observations of the cut surface of necroscopic human lungs that had been air dried in inflation. ${ }^{1} \mathrm{He}$ attributed the lesions to atrophy of lung tissue resulting from overinflation, and this hypothesis appeared in a major textbook of pathology as late as $1940 .{ }^{2}$ Emphysema was redefined as "abnormal permanent enlargement of airspaces distal to terminal bronchioles", ${ }^{3}$ and this definition was modified to include "destruction of alveolar walls without obvious fibrosis". M cLean ${ }^{5}$ and Leopold and Gough ${ }^{6}$ implicated the inflammatory response in the pathogenesis of the centrilobular form of emphysema, but this suggestion was interpreted conservatively because their studies were based on necroscopic specimens that were frequently contaminated by terminal bronchopneumonia.

\section{PATHOLOGY}

The seminal work of MCLean ${ }^{5}$ and Leopold and Gough $^{6}$ established that centrilobular emphysema (CLE) is the result of dilatation and destruction of the respiratory bronchioles (fig 1). Subsequent studies showed that these lesions are larger and more numerous in the upper lung. ${ }^{78}$ The term "focal emphysema" was introduced to describe a form of lung destruction ${ }^{9}$ that has a similar origin but is more widely distributed and less severe than centrilobular emphysema. ${ }^{10}$

Panlobular or panacinar emphysema (PLE) results from a more uniform destruction of all of the acini within the secondary lobule. ${ }^{11}$ Thurlbeck ${ }^{8}$ showed that, in its mildest forms, it is difficult to discern PLE from normal lung unless the lung is fixed in full inflation and carefully examined using low power magnification. In contrast to the centrilobular lesion, panacinar emphysema is more severe in the lower lobes but a predominant lower lobe distribution only becomes statistically significant in severe disease. ${ }^{8}$ Panacinar emphysema is commonly associated with $\alpha_{1}$-antitrypsin deficiency, but is also found in cases where no clearcut genetic abnormality has been identified.

Distal acinar, mantle, and paraseptal emphysema are terms used to describe lesions that occur in the periphery of the lobule along the lobular septae, particularly in the subpleural region. ${ }^{10}$ Localised paraseptal emphysema has been associated with spontaneous pneumothorax in young adults and bullous lung disease in older individuals where individual large cysts may interfere with lung function. Unilateral emphysema or M cLeod's syndrome occurs as a complication of severe childhood infections caused by rubella or adenovirus, and congenital lobar emphysema is a developmental abnormality affecting newborn children. ${ }^{10}$ The emphysema that forms around scars lacks any special distribution in the lobule and is referred to as irregular emphysema. ${ }^{10}$

Leukocyte kinetics in the lung

Leukocyte accumulation in the lung is a feature of emphysema (see below). The traffic of leukocytes through the lung microvessels and their migration out of the vascular space through the tissue and into the airspaces is incompletely understood. The pulmonary circulation receives the entire output of the right ventricle-that is, $\sim 6 \mathrm{l} / \mathrm{min}$ or $8600 \mathrm{I}$ blood in 24 hours. As each litre of blood contains $10^{9}$ leukocytes, the lung receives approximately $8.6 \times 10^{12}$ leukocytes every 24 hours. ${ }^{12}$ The bronchial circulation adds approximately $1 \%$ of the left ventricle output to this value and this increases in disease. The neutrophils are the easiest to keep track of because they do not divide after they enter the circulation from the bone marrow, normally remain inside the vascular space, and do not re-enter the circulation after they migrate out of the microvasculature. ${ }^{12}$ The maximum diameter of the circulating cells is slightly larger than the average capillary but, because the disc shaped erythrocytes are able to fold, they are much more deformable than the spherically shaped leukocytes. ${ }^{12}$ This allows erythrocytes to move through restrictions in lung capillaries much more quickly than leukocytes, and the multisegmented nature of the lung capillary bed allows the faster moving erythrocytes to pass the slower moving neutrophils. ${ }^{12}$ This difference between erythrocyte and leukocyte transit time concentrates the neutrophils with respect to the erythrocytes in the lung capillaries and accounts for the so-called marginated pool of neutrophils in the pulmonary circulation. ${ }^{12}$ Cigarette smoking increases the number of marginated neutrophils in the lung capillary bed. ${ }^{13}$ Only a very small proportion of circulating neutrophils delivered to the lung ever migrates out of the vascular space, even in the presence of strong stimuli such as pneumococcal pneumonia. ${ }^{14}$

Walker and colleagues have shown that the surface of interstitial fibroblasts form a network that guides the neutrophil from its point of exit out of the capillary to the point of entry into the alveolar airspace. ${ }^{15}$ Their work suggests an important interaction between the leukocytes and the 

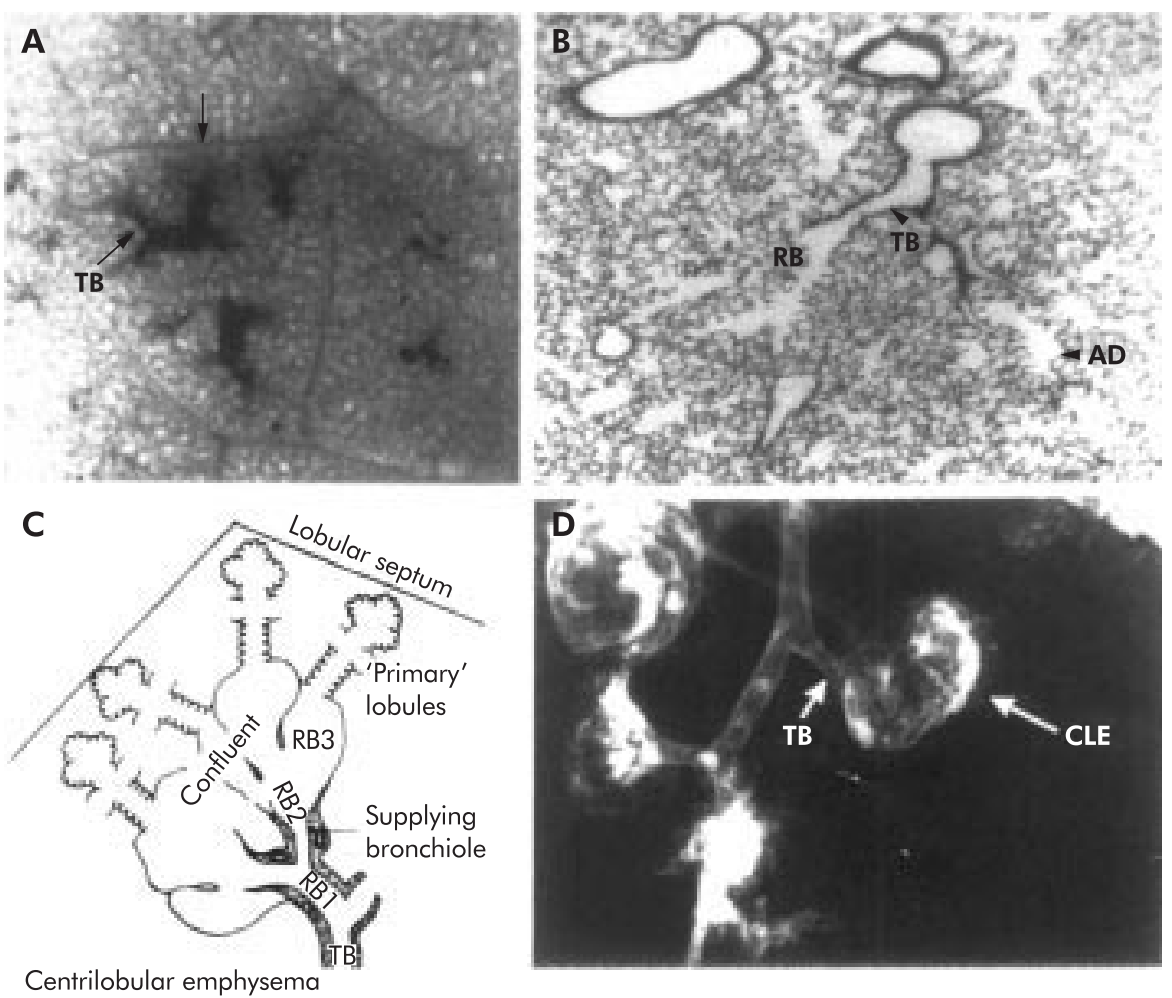

Figure 1 (A) Photograph of a dried necroscopic specimen taken through the pleural surface showing the outline of a secondary lung lobule (arrow) with a bronchogram that outlines the terminal bronchioles (TB) supplying a single lung acinus. (B) Low power photograph showing the histology of a terminal bronchiole supplying a respiratory bronchiole. (C) O riginal line drawing from Leopold and Gough ${ }^{6}$ showing destruction of the respiratory bronchioles in centrilobular emphysema. (D) N ecroscopic bronchogram showing centrilobular emphysema.

surface of the interstitial fibroblast as the neutrophils move through the alveolar wall interstitial matrix. Whether proteolysis of the matrix is necessary for neutrophil emigration remains unsettled. Gelatinase B (M M P-9), for example, has been implicated in some studies, but neutrophils appear to enter tissues normally in gelatinase B-deficient mice. ${ }^{16}$

M onocyte/macrophages and lymphocytes may follow similar pathways but this has not been so well studied. Quantification of the number of cells moving is also much more difficult as they have the ability to divide during their transit through the tissue. The lymphocytes may also follow specialised pathways in the lymphatic system that probably includes traffic through the bronchial associated lymphoid tissue.

\section{PATHOGENESIS}

$M$ any processes appear to be involved in the pathogenesis of emphysema associated with cigarette smoking (fig 2), but the proteinase-antiproteinase hypothesis has prevailed as the central theme for nearly 40 years. ${ }^{17}$ According to this hypothesis, destruction of alveolar walls results from proteinase activity that digests extracellular matrix (ECM). The proteinase-antiproteinase hypothesis has considerable experimental support, but many specifics remain unsettled such as the cell types and proteinases responsible for ECM destruction and the ECM component(s) that are targets of the proteinases.

$\mathrm{Mice}$ are proving to be valuable in analysing the pathogenesis of emphysema associated with cigarette smoking. ${ }^{18}$ Animal models based on the mouse allow early stages of lung injury to be evaluated, where various therapeutic or other types of regimens can be imposed over relatively short experimental periods. Genetic manipulations can be readily accomplished allowing the role of specific gene products to be evaluated. Clearly, genetic factors are critical in the predisposition to emphysema from cigarette smoke exposure in mice. Differences in resistance to developing smoke induced emphysema between several strains of mice, for example, correlate with differences between the strains in the capacity to mount antioxidant responses to cigarette smoke..$^{19}$ In contexts other than smoking, mice have been informative about mechanisms of emphysema and, at times, emphysema has been an unexpected finding in genetically abnormal mice. ${ }^{20}$

What cells are responsible for ECM degradation in emphysema?

The idea that emphysema results from chronic inflammation affecting al veoli and terminal airways has dominated this field ever since the discovery linking emphysema and $\alpha_{1}$ antitrypsin deficiency to neutrophil elastase (NE). Because NE is expressed almost exclusively by neutrophils, and because smokers have more neutrophils in their bronchoalveolar lavage (BAL) fluid than non-smokers, neutrophils have long been considered a major culprit in causing emphysema.

However, macrophages, T lymphocytes, and eosinophils are increasingly being implicated in the pathogenesis of lung destruction in emphysema, and some data even suggest that the presence of neutrophils in alveolar walls in smokers correlates with preservation rather than destruction of alveolar walls. ${ }^{21} \mathrm{~A}$ recent analysis of inflammatory cells in the lung parenchyma and terminal airspaces in surgically resected lungs having no emphysema, mild emphysema, or severe emphysema found increased numbers of neutrophils, macrophages, T lymphocytes, and eosinophils in emphysematous tissue. $^{22}$ The numbers of each inflammatory cell type correlated equally well with the severity of emphysema so that, by cell numbers, no one type of inflammatory cell appeared to predominate. Compared with normal lung, lungs with severe emphysema contained approximately 10 times more of each of the inflammatory cell types.

These results show that a complex inflammatory response exists in the emphysematous lung. Precisely how the various 


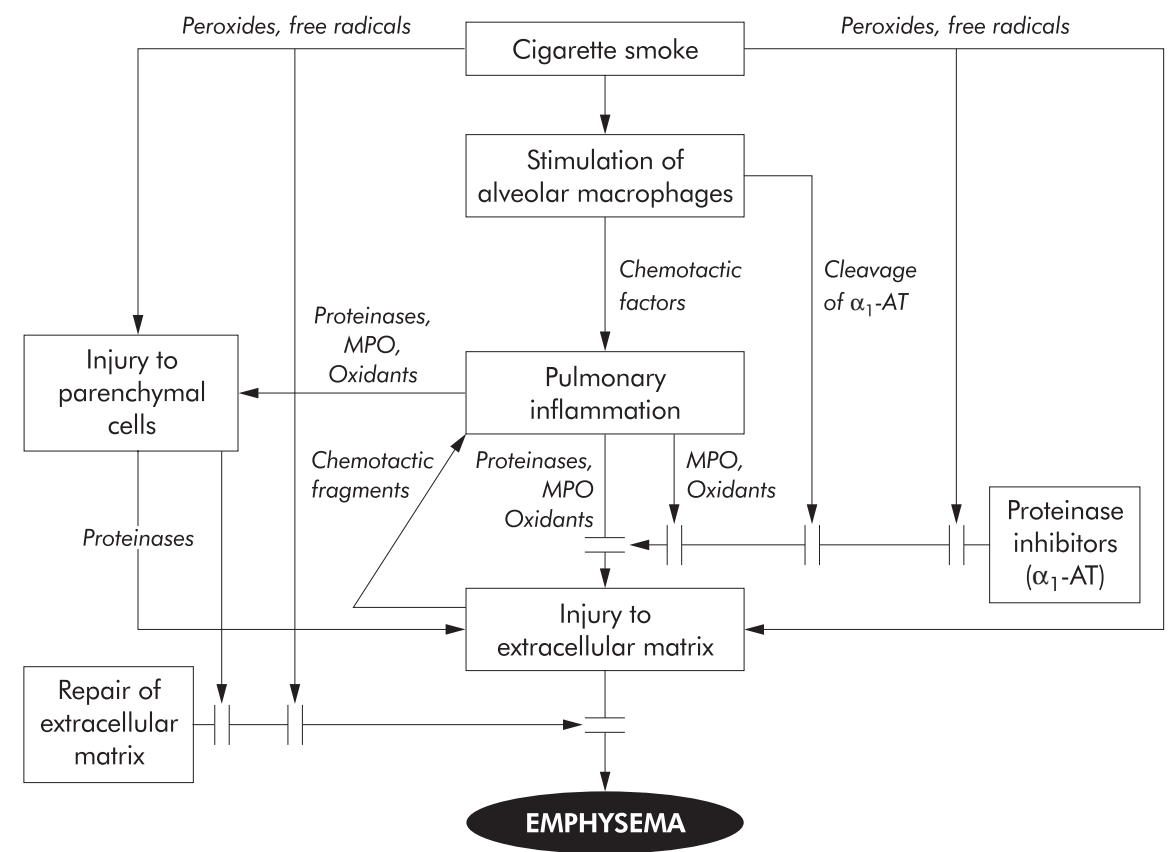

Figure 2 Schematic of the pathogenesis of emphysema showing that smoking causes an accumulation of inflammatory cells in the peripheral tissues of the lungs. The inflammatory cells release proteinases and oxidants that degrade or damage extracellular matrix in the walls of alveoli, alveolar ducts, and respiratory bronchioles. Lung cells, such as alveolar type II cells, may be stimulated to produce and release proteinases that replicate the effects of the proteinases released by inflammatory cells. A gents from inflammatory cells also inactivate intrapulmonary proteinase inhibitors, injure lung cells that make extracellular matrix, and interfere with normal processing of extracellular matrix molecules. Components of the tobacco smoke may have some of the same detrimental effects as the products of inflammatory cells.

inflammatory cell types contribute to the destruction of alveolar walls is yet to be determined, but a reasonable speculation would be that neutrophils, macrophages, and eosinophils degrade alveolar ECM directly by releasing proteinases whereas $T$ lymphocytes influence inflammatory cell recruitment and the function of inflammatory cells that release proteinases. The remarkable expansion of the alveolar macrophage population in many smokers' lungs may be important in producing alveolar destruction, even though proteinase release per cell may be similar between smokers with emphysema and smokers who do not have emphysema. ${ }^{23}$

An intriguing feature of these recent data is that the markedly increased number of inflammatory cells in severe emphysema was present even in individuals who had stopped smoking years earlier. ${ }^{22}$ This finding fits with the clinical situation of progressive deterioration of lung function among some former smokers with COPD. The mechanisms that perpetuate recruitment of inflammatory cells in lung tissue long after the primary stimulus-namely, cigarette smoke-has been removed are not known, but peptides derived from ECM are chemotactic for inflammatory cells ${ }^{24}$ which suggests that destruction of ECM may be self-perpetuating.

Inflammatory cells may not be the only source of proteinases that degrade alveolar septal ECM. Alveolar epithelial cells in lungs removed for lung transplantation for COPD and in lung tissues resected at lung volume reduction surgery express the collagenase matrix metalloproteinase 1 (MMP-1) mRNA and protein, and exhibit collagenase activity. ${ }^{25}$ Similarly, in guinea pigs exposed to cigarette smoke, MM Ps are expressed by lung structural cells. ${ }^{26}$ However, it is important to note that expression of MMPs by alveolar epithel ium or other structural cells does not necessarily lead to emphysema as it also occurs in interstitial lung diseases. ${ }^{27}$

While intrapulmonary inflammation appears to be a consistent feature of smoking and emphysema, three recent studies in rodents illustrate that emphysema can develop with minimal or no inflammation. Rats exposed to agents that interfere with the function of vascular endothelial growth factor (VEGEF) receptors have apoptosis of al veolar epithelial cells and capillary endothelial cells and develop emphysemalike lungs. ${ }^{28} 29$ TIM P-3 “knockout" mice undergo pathological alveolar enlargement beginning around 2 weeks postpartum without an increase in inflammatory cells. ${ }^{30} \mathrm{~A}$ single intratracheal instillation of $\beta$-D-xyloside in rats is followed by disturbed proteoglycan synthesis, parenchymal destruction, and airspace enlargement comparable to that attained with intratracheal pancreatic elastase and it occurs without inflammation. ${ }^{31}$ The relevance of these models to human emphysema is not clear, but the models suggest that diverse homeostatic mechanisms are required to preserve normal lung structure.

What proteinases are responsible for alveolar septal destruction in emphysema?

The diversity of inflammatory cell types in emphysematous tissue and the variety of proteinases produced by these cells raise the strong possibility that many proteinases might be involved in emphysematous lung destruction. This diversity also suggests that there might be differences between individuals and even in the same individual at different times.

With the exception of emphysema associated with $\alpha_{1}{ }^{-}$ antitrypsin deficiency, in which NE appears to be the critical proteinase, conclusively identifying the key enzymes in emphysema pathogenesis has proved difficult. The present brief discussion will focus on neutrophil elastase and M MPs because these are the proteinases most associated with emphysema.

The possibility that NE is important in emphysema even among smokers with normal levels of $\alpha_{1}$-antitrypsin has considerable support. For example, smoking increases NE in BAL fluid, ${ }^{32}$ and smokers with CT scan evidence of emphysema have higher levels of neutrophil specific proteinases including NE in their BAL fluid than smokers without emphysema. ${ }^{33}$ The role of NE in causing emphysema may be principally via its capacity to degrade the elastin in elastic fibres, but other mechanisms may also operate. M ice lacking NE as a result of 
Table 1 Matrix metalloproteinases (M M Ps) in human emphysema

\begin{tabular}{|c|c|c|c|c|}
\hline Author (ref) & $\begin{array}{l}\text { Emphysema } \\
\text { detection }\end{array}$ & Test samples & Observations & Comments \\
\hline Finla ${ }^{50}$ & $\mathrm{CT}$ & $\begin{array}{l}\text { AM mRN A and culture } \\
\text { media }\end{array}$ & $\begin{array}{l}\uparrow \text { collagenase } 1 \text { (M M P-1) } \uparrow \text { gelatinase } \\
\text { B (M M P-9) }\end{array}$ & $\begin{array}{l}\text { No increase in expression of macrophage elastase } \\
\text { (M M P-12) }\end{array}$ \\
\hline Finlay $^{51}$ & $\mathrm{CT}$ & BAL fluid & $\begin{array}{l}\uparrow \text { collagenase activity } \uparrow \text { gelatinase B } \\
(\text { M M P-9) }\end{array}$ & MMPs probably neutrophil derived \\
\hline O hnishi ${ }^{41}$ & Histology & Lung tissue from LVRS & $\begin{array}{l}\uparrow \text { M T-M M P-1 (M M P-14) } \uparrow \text { gelatinase } \\
\text { A (M M P-2) }\end{array}$ & $\begin{array}{l}\text { No increase in expression of macrophage elastase } \\
\text { (M M P-12) }\end{array}$ \\
\hline Betsuya ku ${ }^{33}$ & CT & $\begin{array}{l}\text { BAL fluid and AM culture } \\
\text { media }\end{array}$ & $\begin{array}{l}\uparrow \text { collagenase } 2 \text { (M M P-8), } \uparrow \\
\text { gelatinase B (M M P-9) }\end{array}$ & $\begin{array}{l}\text { M M Ps in BAL fluid from inflammatory cells; no } \uparrow \\
\text { gelatinase B (M M P-9) in AM culture media in } \\
\text { emphysema }\end{array}$ \\
\hline Segura-Valdez ${ }^{52}$ & Histology & $\begin{array}{l}\text { Lung tissue from autopsy } \\
\text { and LVRS; BAL fluid }\end{array}$ & $\begin{array}{l}\uparrow \text { collagenases } 1,2,3 \text { (M M Ps }-1,-8, \\
-13) \uparrow \text { gelatinases A, B (M M Ps }-2,-9 \text { ) }\end{array}$ & $\begin{array}{l}\text { M M Ps are expressed by both inflammatory cells and } \\
\text { structural cells of the lung }\end{array}$ \\
\hline Imai ${ }^{25}$ & Histology & $\begin{array}{l}\text { Lung tissue from lung } \\
\text { transplant and LVRS }\end{array}$ & $\uparrow$ collagenase 1 (M M P-1) & $\begin{array}{l}\text { Collagenase expressed by type II cells. N o increase in } \\
\text { expression ofmacrophage elastase (M M P-12) }\end{array}$ \\
\hline$M$ inematsu $^{40}$ & CT & Cellular DN A & $\begin{array}{l}\uparrow \text { gelatinase B (M M P-9) polymorphism } \\
\text { in smokers with emphysema }\end{array}$ & $\begin{array}{l}\text { This polymorphism also associated with an increased } \\
\text { incidence of coronary atherosclerosis }\end{array}$ \\
\hline
\end{tabular}

gene targeting show some protection from cigarette smoke induced emphysema caused by decreases in alveolar recruitment of neutrophils and monocytes, macrophage elastase activation, and degradation of TIM P-1, an inhibitor of macrophage elastase. $^{35}$

Over the past few years M M Ps have gained support as proteinases involved in alveolar destruction in emphysema ${ }^{36}$ as this family of enzymes is associated with both physiological and pathological remodelling in many tissues including the lung. ${ }^{37}$ As a group, MMPs can degrade all components of the ECM . M embers of the M M P family of enzymes are present in low to undetectable levels in normal lung, but are readily detected in many lung diseases. Macrophages can synthesise several MMPs. In contrast, neutrophils do not synthesise MMPs once they have completed their development in the bone marrow, but they carry in their granules two MMPsM M P-8 (neutrophil collagenase) and M M P-9 (gelatinase B). It is important to note that the expression of MMPs is not restricted to inflammatory cells; virtually all cells including alveolar epithelial cells and fibroblasts can make M M Ps. Also, the potential substrates of MMPs are not limited to ECM as many other proteins, including $\alpha_{1}$-antitrypsin, are also cleaved by these enzymes. ${ }^{38}$

Several M M Ps have been implicated in the pathogenesis of emphysema (table 1). Interpretation of these data is difficult, however, because (1) most of it comes from moderate or advanced emphysema, (2) different types of samples have been analysed ranging from BAL fluid, alveolar macrophages in culture, to surgically resected lung tissue, and (3) the types of M M P measurements have been diverse, varying from enzymatic activity to immunological assays so that the issue of pro-enzymes versus active forms is not clear. M oreover, studies of alveolar macrophages in culture and of BAL fluid raise questions about the relationship of the findings to what is actually occurring in the tissue in vivo. Despite these concerns, at least two interesting findings have emerged:

- structural cells of the lung may be responsible for some M M P production; and

- M M P-12 (macrophage elastase) is not prominent in human emphysema even though it is critical for smoking induced emphysema in the mouse. ${ }^{39}$

As shown in table 1, the M M Ps associated with emphysema include the collagenases M M P-1, which is typically produced by fibroblasts, and MMP-8 which is found primarily in neutrophils. Because alveolar septal collagen turnover appears to occur in emphysema ( see bel ow), it would not be surprising if MMP-1 and MMP-8 have a role in alveolar septal destruction. Guinea pigs with cigarette smoke induced emphysema show collagenase mRNA and collagenase protein in alveolar macrophages, alveolar epithelial and interstitial cells, and have collagenase activity in lung homogenates, unlike lungs from control animals. ${ }^{26}$

Also associated with emphysema are the so-called gelatinases MMP-2 and MMP-9. These proteinases degrade a number of ECM components, including type IV collagen and elastin. ${ }^{37}$ Neutrophils contain abundant M M P-9 that is readily released when the cells are stimulated. A polymorphism in the promoter of MMP-9 has been associated with an increased incidence of emphysema among smokers of comparable age ( $\sim 65$ years) and smoking history ( $\sim 00$ pack years) ${ }^{40}$ I ncreases in MMP-14 (also called MT-1 MMP) found in one study are intriguing, ${ }^{41}$ as this proteinase has a key role in the activation of M M P-2 in a process that occurs on cell surfaces.

Human alveolar macrophages make M M P-12 (also called macrophage elastase), ${ }^{42}$ but its production appears to be less relative to other MMPs and much less than murine macrophages. This difference, and the fact that M M P-12 has not been found in several studies, ${ }^{25}{ }^{41} 43$ suggests that, with regard to this enzyme, the mouse and human differ.

What alveolar septal ECM component(s) are targets in the pathogenesis of emphysema?

Many of the early experimental studies supporting the proteinase-antiproteinase hypothesis pointed to elastin as the critical target of proteinases that cause emphysema. ${ }^{42}$ Indeed, this emphasis was so dominant that the hypothesis has also been labelled the "elastase-antielastase" hypothesis. ${ }^{38}$ Clearly, destruction of alveolar elastin does lead to emphysema experimentally and frayed elastic fibres are evident in alveolar tissue in human emphysema ${ }^{43}$ However, focus on the importance of elastic fibres has obscured the fact that destruction of alveolar walls affects other ECM components, of which collagens are the most prominent quantitatively and morphologically. Interestingly, when experiments involving intratracheal instillation of enzymes to produce emphysema were in vogue a few decades ago, none was done with mammalian collagenases nor have such experiments been done yet.

Experimental studies as well as examinations of human tissue point to collagen breakdown and resynthesis in emphysema. ${ }^{44}$ The likelihood that collagen turnover is a feature of the pathogenesis of emphysema is underscored by the prevalence of increased collagenolytic enzymes in human emphysema (table 1) and a small body of experimental data. ${ }^{45}$ Reductions in lung collagen can occur quickly in response to exposure to cigarette smoke, as increased levels of collagenous peptides are present in the BAL fluid of mice within 1 day of exposure to smoke from two cigarettes. ${ }^{46} \mathrm{How}-$ ever, with chronic exposure in mice there is increased lung collagen concurrent with the development of emphysema, ${ }^{47}$ results that match observations of increased lung collagen 
content in human emphysema. ${ }^{48} 49$ Clearly, emphysema involves more than elastin degradation. Indeed, it is likely that the lung remodelling recognised as emphysema involves destruction and synthesis of all components of the lung ECM .

\section{Authors' affiliations}

J C Hogg, The University of British Columbia M CDonald Research Laboratory, St Paul's Hospital, Vancouver, Canada

R M Senior, Pulmonary and C ritical Care M edicine, Department of Medicine, and Department of Cell Biology and Physiology, W ashington University School of Medicine and Barnes-Jewish Hospital, St Louis, M issouri, USA

$\mathrm{JCH}$ is supported in part by the $\mathrm{C}$ anadian Institutes of Health Research and the N HLBI/ N IH. RM S is supported in part by N HLBI/ N IH and the Alan $A$ and Edith $L$ W olff CharitableTrust.

\section{REFEREN CES}

1 Laennec RTH. A treatise on diseases of the chest and on mediate auscultation. Translated by Forbes J. 4 th ed. London: Longmans, 1834.

2 McCallum WG. Types of injury: destruction of the respiratory tract. In: $A$ textbook of pathology. 7 th ed. Philadelphia: W B Saunders, 1940: 419-28.

3 Ciba Guest Symposium Report. Terminology, definitions and classifications of chronic pulmonary emphysema and related conditions. Thorax 1959;14:286-99

4 Snider GL, Kleinerman JL, Thurlbeck W M, et al. Definition of emphysema. Report of a N ational Heart, Lung and Blood Institute, Division of Lung Diseases. Am Rev Respir Dis 1985;132:182-5.

5 McLean KH. M icroscopic anatomy of pulmonary emphysema. A ust Ann Intern Med 1956;5:73-88.

6 Leopold J G, G ough J. Centrilobular form of hypertrophic emphysema and its relation to chronic bronchitis. Thorax 1957;12:219-35.

7 Heard BE. Further observations on the pathology of pulmonary emphysema in chronic bronchitis. Thorax 1958;14:58-90.

8 Thurlbeck WM. The incidence of pulmonary emphysema with observations on the relative incidence and spatial distribution of various types of emphysema. Am Rev Respir Dis 1963:87:207-15.

9 Heppleston AG, Leopold JG. Chronic pulmonary emphysema: a na tomy and pathogenesis. Am J Med 1961;31:279-91.

10 Dunnill MS. Emphysema. In: Pulmonary pathology. Edinburgh: Churchill Livingstone, 1982: 81-112.

11 Wyatt JP, Fischer VW, Sweet AC. Panlobular emphysema: ana tomy and pathogenesis. Dis Chest 1962:41:239-59.

12 Hogg JC. N eutrophil kinetics and lung injury. Physiol Rev 1987;67:1249-95

13 MacNee W, W iggs B, Belzberg AS, et al. The effect of cigarette smoking on neutrophil kinetics in human lungs. $N$ Engl J Med $1989 ; 321: 924-8$

14 Doerschuk CM, Markos J, Coxson HO, et al. Q uantification of neutrophil migration in acute bacterial pneumonia in rabbits. J Appl Physiol 1994;77:2593-9.

15 Behzad A, Chu F, W alker DC. Fibroblasts are in a position to provide directional information to migrating neutrophils during pneumonia in rabbit lungs. Microvasc Res 1996;51:303-16.

16 Betsuyaku T, Shipley JM, Liu Z, et al. N eutrophil emigration in the lungs, peritoneum, and skin does not require gelatinase B. Am J Respir Cell Mol Biol 1999;20:1303-9.

17 Shapiro SD. The pathogenesis of emphysema: the elastase:antielastase hypothesis 30 years later. Proc Assoc Am Phys 1995;107:346-52.

18 Dawkins PA, Stockley RA. A nimal models of chronic obstructive pulmonary disease. Thorax 2001:56:972-7.

19 Cavarra E, Bartalesi B, Lucattelli $M$, et al. Effects of cigarette smoke in mice with different levels of $\alpha 1$-proteinase inhibitor and sensitivity to oxidants. Am J Respir Crit Care Med 2001;164:886-90.

20 Shibata $Y$, Zsengeller Z, 0 take K, et al. Alveolar macrophage deficiency in osteopetrotic mice deficient in macrophage colony-stimulating factor is spontaneously corrected with age and associated with matrix metalloproteinase expression and emphysema. Blood 2001;98:284552.

21 Finkelstein R, Fraser RS, G hezzo H, et al. Alveolar inflammation and its relation to emphysema in smokers. Am J Respir C rit Care Med $1995 ; 152: 1666-72$

22 Retamales I, Elliott W M, M eshi B, et al. A mplification of inflammation in emphysema and its association with latent adenoviral infection. A m J Respir Crit Care Med 2001;164:469-73; comments 2001;164:339; correspondence 2001;165:730-1.

23 Abboud RT, 0 fulue AF, Sansores RH, et al. Relationship of alveolar macrophage plasminogen activator and elastase activities to lung function and CT evidence of emphysema. Chest 1998;113:1257-63.
24 Senior RM, G riffin G L, M echam RP, et al. Val-G ly-Val-Ala-Pro-G ly, a repeating peptide in elastin, is chemotactic for fibroblasts and monocytes. J Cell Biol 1984;99:870-4

25 Imai K, Dalal SS, Chen ES, et al. Human collagenase (matrix metalloproteinase-1) expression in the lungs of patients with emphysema. Am J Respir Crit Care Med 2001;163:786-91.

26 Selman M, Montano M, Ramos C, et al. Tobacco smoke-induced lung emphysema in guinea pigs is associated with increased interstitial collagenase. Am J Physiol 1996;271: L734-43.

27 Suga $\mathrm{M}$, lyonaga $\mathrm{K}, \mathrm{O}$ kamoto $\mathrm{T}$, et al. Characteristic elevation of matrix metalloproteinase activity in idiopathic interstitial pneumonias. A $\mathrm{m} J$ Respir Crit Care Med 2000;162:1949-56.

28 Kasahara Y, Tuder RM, Tara seviciene-Stewart L, et al. Inhibition of VEG F receptors causes lung cell apoptosis and emphysema. J Clin Invest 2000;106:1311-9.

29 Kasahara Y, Tuder RM, Cool CD, et al. Endothelial cell death and decreased expression of vascular endothelial growth factor and vascular endothelial grow th factor receptor 2 in emphysema Am J Respir Crit Care Med 2001;163:737-44

30 Leco $\mathrm{KJ}, \mathrm{W}$ aterhouse $\mathrm{P}$, Sanchez $\mathrm{OH}$, et al. Spontaneous air space enlargement in the lungs of mice lacking tissue inhibitor of metalloproteina ses-3 (TIM P-3). I Clin Invest 2001;108:817-29.

31 Van Kuppevelt TH, van de Lest $\mathrm{CH}$, Versteeg EM, et al. Induction of emphysematous lesions in rat lung by beta-D-xyloside, an inhibitor of proteoglycan synthesis. Am J Respir Cell M ol Biol 1997;16:75-84.

32 Fera T, Abboud RT, Richter A, et al. A cute effect of smoking on elastaselike esterase activity and immunologic neutrophil elastase levels in bronchoalveolar lavage fluid. Am Rev Respir Dis 1986;133:568-73.

33 Betsuyaku T, N ishimura M, Takeyabu K, et al. N eutrophil granule protein in bronchoalveolar lavage fluid from subjects with subclinical emphysema. Am J Respir Crit Care M ed 1999;159:1985-91.

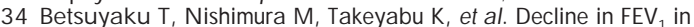
community-based older volunteers with higher levels of neutrophil elastase in bronchoalveolar lavage fluid. Respiration 2000;67:261-7.

35 Goldstein NM, Kobayashi DK, Kelley D, et al. N eutrophil elastase contributes to cigarette smoke-induced emphysema in mice. 2002 (sub mitted).

36 Pardo A, Selman M. Proteinase-antiproteinase imbalance in the pathogenesis of emphysema: the role of metalloproteinases in lung damage. Histol Histopathol 1999;14:227-33.

37 Parks WC, Shapiro SD. M atrix metalloproteinases in lung biology. Respir Res 2001;2:10-19.

38 Shapiro SD, Senior RM. M atrix metalloproteinases. M atrix degradation and more. Am J Respir Cell Mol Biol 1999;20:1100-2.

39 Hautamaki RD, Kobayashi DK, Senior RM, et al. Requirement for macrophage elastase for cigarette induced emphysema in mice. Science $1997 ; 277: 2002-4$

40 Minematsu $\mathrm{N}, \mathrm{N}$ akamura $\mathrm{H}$, Tateno $\mathrm{H}$, et al. $\mathrm{G}$ enetic polymorphism in matrix metalloproteinase-9 and pulmonary emphysema. Biochem Biophys Res Commun 2001;289:116-9.

41 Ohnishi K, Takagi M, Kurokawa Y, et al. Matrix metallop roteinase-mediated extracellular matrix protein degradation in human pulmonary emphysema. Lab Invest 1998:78:1077-87.

42 Snider GL, Hayes JA, Franzblau C, et al. Relationship between elastolytic activity and experimental emphysema-induced properties of papain preparations. Am Rev Respir Dis 1974;110:254-62.

43 Fukuda $Y$, M asuda $Y$, Ishizaki M, et al. M orphogenesis of abnormal elastic fibers in lungs of patients with panacinar and centriacinar emphysema. Hum Pathol 1989;20:652-9.

44 Foronjy R, D'A rmiento J. The role of collagenase in emphysema. Respir Res 2001;2:348-52.

45 D'Armiento J, Dalal SS, 0 kada Y, et al. Collagenase expression in the lungs of transgenic mice causes pulmonary emphysema. Cell $1992 ; 71: 955-61$

46 Dhami R, G ilks B, Xie C, et al. A cute cigarette smoke-induced connective tissue breakdown is mediated by neutrophils and prevented by alpha-1-antitrypsin. Am J Respir Cell M ol Biol 2000;22:244-52.

47 Wright JL. Churg A. Smoke-induced emphysema in guinea pigs is associated with morphometric evidence of collagen breakdown and repair. Am J Physiol 1995;268: L17-20.

48 Lang MR, Fiaux GE, Gillooly M, et al. Collagen content of alveolar wall tissue in emphysematous and non-emphysematous lungs. Thorax 1994:49:319-26.

49 Vlahovic G, Russell M L, M ercer RR, et al. Cellular and connective tissue changes in alveolar septal walls in emphysema. Am J Respir Crit Care Med 1999;160; 2086-92.

50 Finlay GA, 0 'D riscoll LR, Russell KJ, et al. M atrix metallop roteina se expression and production by alveolar macrophages in emphysema. Am J Respir Crit Care Med 1997;156:240-7.

51 Finlay GA, Russell KJ, M cM ahon KJ, et al. Elevated levels of matrix metalloproteinases in bronchoalveolar lavage fluid of emphysematous patients. Thorax 1997;52:502-6.

52 Segura-Valdez L, Pardo A, Gaxiola M, et al. Upregulation of gelatinases $A$ and $B$, collagenases 1 and 2 , and increased parenchymal cell death in COPD. Chest $2000 ; 117: 684-94$ 